\title{
Effect of Deformation Temperature on Low-Cycle Fatigue Properties of Fe-28Mn-6Si-5Cr Shape Memory Alloy
}

\author{
Wataru Tasaki ${ }^{1,2,{ }^{*} 1,{ }^{* 2}}$, Takahiro Sawaguchi ${ }^{1}$, Ilya Nikulin ${ }^{1}$, Kaoru Sekido ${ }^{1}$ and Koichi Tsuchiya ${ }^{1,2}$ \\ ${ }^{1}$ National Institute for Materials Science, Tsukuba 305-0047, Japan \\ ${ }^{2}$ University of Tsukuba, Tsukuba 305-8577, Japan
}

\begin{abstract}
Effect of deformation temperature on low-cycle fatigue properties of an Fe-28Mn-6Si-5Cr shape memory alloy was investigated. Cyclic push-pull loadings at a total strain range of 0.02 were applied to the alloy at various deformation temperatures ranging from 223 to $523 \mathrm{~K}$. The microstructures and fracture surfaces in the fatigue tested samples were analyzed by means of X-ray diffraction, scanning electron microscopy and electron backscattering diffraction. The highest fatigue life of 22,400 cycles was obtained at $423 \mathrm{~K}$. Increasing or decreasing the deformation temperature resulted in a decrease in fatigue life to several thousand cycles. The specimens deformed to fatigue fracture at temperatures below $298 \mathrm{~K}$ exhibited microstructures with $\varepsilon$-martensite and brittle characteristics of the fracture surface, while the specimens deformed above $473 \mathrm{~K}$ exhibited the single $\gamma$-phase and ductile characteristics of the fracture surface. The deformation at $423 \mathrm{~K}$ resulted in a moderate amount of the $\varepsilon$-martensite and a mixed brittle/ductile fracture surface patterns. It is suggested that the highest fatigue life can be obtained when the fatigue temperature lies between $M_{\mathrm{s}}{ }^{\sigma}$ and $M_{\mathrm{d}} . \quad$ [doi:10.2320/matertrans.MBW201503]
\end{abstract}

(Received October 14, 2015; Accepted February 22, 2016; Published April 1, 2016)

Keywords: martensitic transformation, shape memory alloy, low-cycle fatigue, seismic damping, e-martensite, electron backscattering diffraction, fractography, phase stability, stacking fault energy

\section{Introduction}

Fe-Mn-Si-based alloys are well known to exhibit a shape memory effect associated with a deformation-induced martensitic transformation from $\gamma$-austenite with a face centered cubic (FCC) structure to $\varepsilon$-martensite with a hexagonal closepacked (HCP) structure and its reversion on subsequent heating $^{1)}$. Fe-Mn-Si-based alloys have been attracted much attention as low-cost shape memory alloys, and have been utilized in connecting tools, such as pipe joints and crane-rail fish plates $^{2)}$. Recently, Sawaguchi et al. reported that Fe-Mn-Sibased alloys exhibit superior low-cycle fatigue (LCF) properties owing to a reversible $\gamma \leftrightarrow \varepsilon$ transformation under alternative tension-compression loading, and proposed a design concept for improving LCF life ${ }^{3)}$ of the Fe-Mn-Si-based alloys. A suitable application of the fatigue-resistant $\mathrm{Fe}-\mathrm{Mn}-\mathrm{Si}$ alloys is seismic damping of buildings ${ }^{4)}$. An Fe-15Mn-10Cr$8 \mathrm{Ni}-4 \mathrm{Si}$ seismic damping alloy was developed based on the design concept and has been applied to a skyscrapers, recently.

Recent report ${ }^{3)}$ on the LCF properties of ferrous high-Mn alloys with various compositions have revealed that, there are three necessary conditions to improve the LCF life: (i) stacking fault energy (SFE) being $\Gamma \approx 20 \mathrm{mJm}^{-2}$, or thermodynamic phase stability balance between the $\gamma$ - and $\varepsilon$-phases, (ii) suppression of the $\alpha^{\prime}$-phase formation and (iii) addition of Si of approximately 4 mass $\%$. These factors determine the deformation modes of the alloy. High-Mn austenitic steels show various deformation modes, such as $\varepsilon$ - and $\alpha^{\prime}$-martensitic transformation, deformation $\gamma$-twinning, and extended or perfect dislocation slip, depending on the relative phase stabilities and the SFE of the $\gamma$-austenite ${ }^{5,6)}$.

Deformation temperature can also affect the fatigue life of the Fe-Mn-Si-based alloys, because the deformation tem-

\footnotetext{
${ }^{* 1}$ Corresponding author, E-mail: TASAKI.Wataru@nims.go.jp

${ }^{* 2}$ Graduate Student, University of Tsukuba
}

perature strongly affects the phase stability and the SFE in the austenite. However, the effect of deformation temperature on LCF properties in the Fe-Mn-Si-based alloys has not been reported yet. In this report, the temperature dependence of fatigue properties of an $\mathrm{Fe}-28 \mathrm{Mn}-6 \mathrm{Si}-5 \mathrm{Cr}$ shape memory alloy $\left(M_{\mathrm{s}}=314 \mathrm{~K}, A_{\mathrm{f}}=403 \mathrm{~K}\right)$, was investigated at various temperatures ranging from $223 \mathrm{~K}$ (below $M_{\mathrm{S}}$ ) to $523 \mathrm{~K}$ (above $A_{\mathrm{f}}$ ). The fatigue microstructures and fracture surfaces were also observed. The effect of the phase stability and the SFE of the austenite on LCF properties are discussed.

\section{Experimental}

An $\mathrm{Fe}-28 \mathrm{Mn}-6 \mathrm{Si}-5 \mathrm{Cr}$ (mass\%) alloy ingot was produced by high frequency induction melting. The ingot was hot forged and rolled at $1273 \mathrm{~K}$ into rods with a cross section of $17.5 \mathrm{~mm}$ square. They were then subjected to solution annealing for 1 hour at $1237 \mathrm{~K}$ followed by water quenching. Cylindrical LCF test samples and rectangular tensile test samples with the dimensions shown in Fig. 1(a) and (b), respectively, were machined from the annealed rods. LCF tests
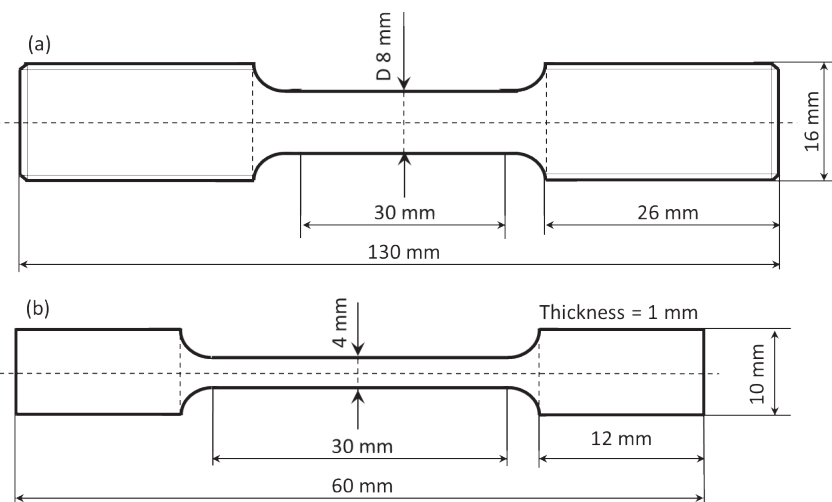

Fig. 1 Schematic illustrations for (a) fatigue test and (b) tensile test. 

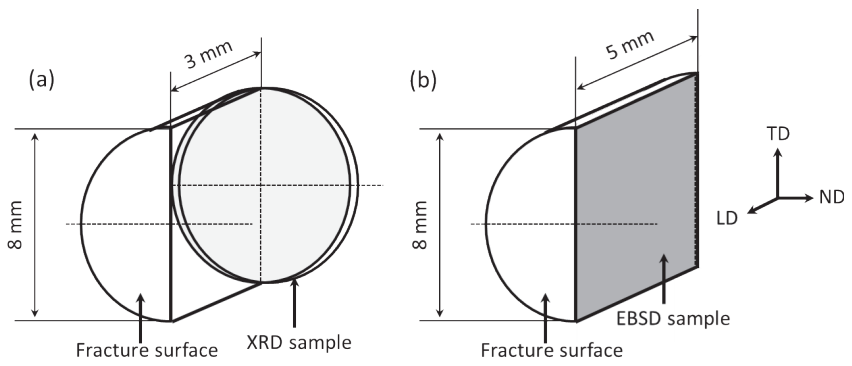

Fig. 2 Schematic illustrations of samples used for (a) XRD and (b) SEMEBSD analysis.

were carried out with a symmetrical tension-compression loading under total strain control mode at a total strain range of 0.02. Fatigue samples were deformed at a strain rate of $4.0 \times 10^{-3} \mathrm{~s}^{-1}$ at temperatures ranging from $223 \mathrm{~K}$ to $523 \mathrm{~K}$ using a servo-hydraulic testing machine. In order to examine the deformation-induced martensitic transformation behavior at various deformation temperatures, tensile testing was carried out at the strain rate of $2.5 \times 10^{-4} \mathrm{~s}^{-1}$ in the same temperature range.

The constituent phases after tensile and LCF tests were determined by X-ray diffraction (XRD) analysis, and the internal microstructures were observed by scanning electron microscopy (SEM) with electron backscattered diffraction (EBSD) analysis. The samples for XRD and the EBSD analysis were sectioned in a manner as shown in Fig. 2(a) and (b), respectively.

The XRD samples were prepared by mechanical grinding with $\mathrm{SiC}$-emery papers and then were chemically polished in a 1:10 solution of hydrofluoric acid and hydrogen peroxide, and etched in hydrochloric acid in order to remove the surface layer damaged by machining. XRD measurements are carried out with using a monochromatized $\mathrm{Co}-\mathrm{K} \alpha_{1}$ radiation at $40 \mathrm{kV}$ and $35 \mathrm{~mA}$ with a scan step of $0.05^{\circ}$. Fatigue fracture surfaces were observed using a ZEISS SIGMA scanning electron microscope at an accelerating voltage of $25 \mathrm{kV}$. The deformation microstructures and their crystallographic characteristics were analyzed with the ZEISS SIGMA SEM equipped with an EBSD analyzer and TSL-OIM software. The samples for EBSD analysis were electro-chemical polished at $30 \mathrm{~V}$ using an electrolyte of ethanol: water: butyl-cellosolve: hydrochloric acid $=35: 6: 5: 4$.

\section{Results}

\subsection{Mechanical properties}

Figure 3 shows the temperature dependence of the tensile $0.2 \%$ proof stress, $\sigma_{0.2}$, in the present alloy. $M_{s}, A_{\mathrm{s}}$, and $A_{\mathrm{f}}$ of the alloy measured by differential scanning calorimetry (DSC) are also indicated by arrows in the Fig. 3. The slope of the proof stress versus temperature $\left(\sigma_{0.2}-T\right)$ curve is negative below $298 \mathrm{~K}$, positive between $298 \mathrm{~K}$ and $373 \mathrm{~K}$, and negative above $373 \mathrm{~K}$. The positive temperature dependence of the $\sigma_{0.2}$ in the medium temperature range just above the $M_{\mathrm{s}}$ indicates that the onset of plastic deformation is dominated by the stress-induced $^{7)}$ or stress-assisted ${ }^{8)} \gamma \rightarrow \varepsilon$ martensitic transformation. The slope of the $\sigma_{0.2}-T$ curve changes from positive to negative at about $373 \mathrm{~K}$. This critical temperature is

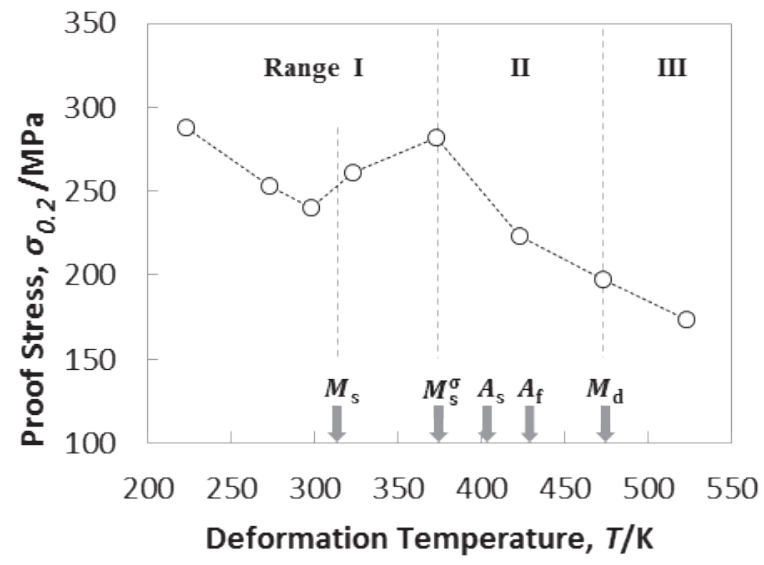

Fig. 3 Effect of the deformation temperature on $0.2 \%$ proof stress of $\mathrm{Fe}$ $28 \mathrm{Mn}-6 \mathrm{Si}-5 \mathrm{Cr}$ alloy.
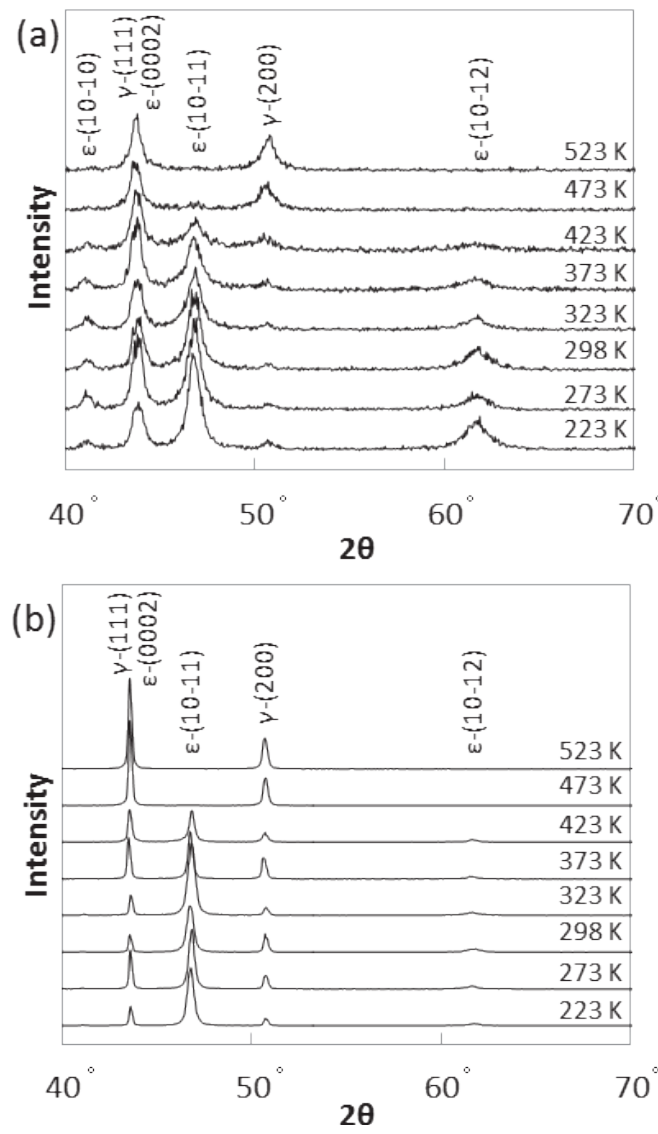

Fig. 4 XRD patterns obtained from samples after (a) uniaxial tensile deformation (b) push-pull deformation at temperatures between $223 \mathrm{~K}$ and $523 \mathrm{~K}$.

so-called the $M_{\mathrm{s}}{ }^{\sigma}$ temperature, above which the critical stress for inducing the martensitic transformation exceeds the yield stress of the parent $\gamma$-phase and the dislocation glide governs the plastic yielding. However, even above the $M_{\mathrm{s}}{ }^{\sigma}$ temperature, the deformation-induced $\gamma \rightarrow \varepsilon$ martensitic transformation is still possible with the aid of dislocations that serve as nucleation sites for the $\varepsilon$-martensite, referred to as strain-induced martensitic transformation. Figure 4(a) and (b) show XRD patterns of the alloy tested in the temperature interval from $223 \mathrm{~K}$ to $523 \mathrm{~K}$ under monotonic tensile loading and cyclic loading, respectively. The intensity of martensite peaks 
(a)

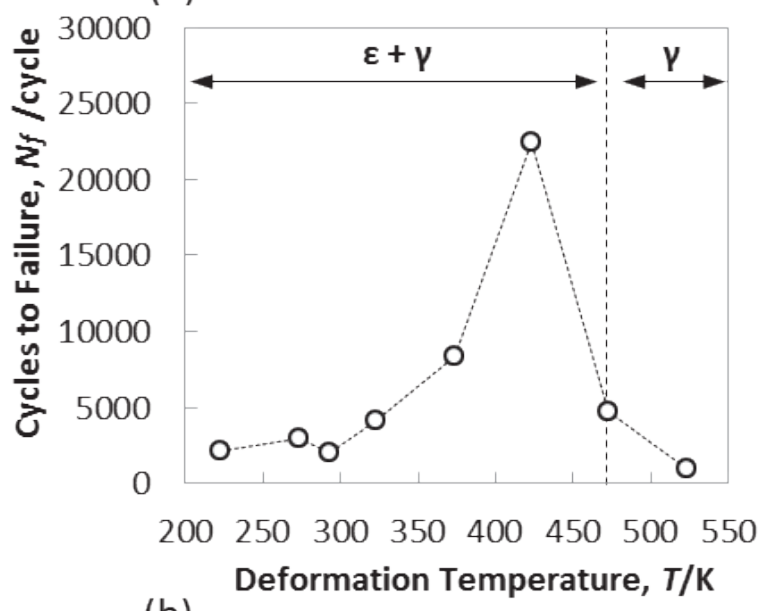

(b)

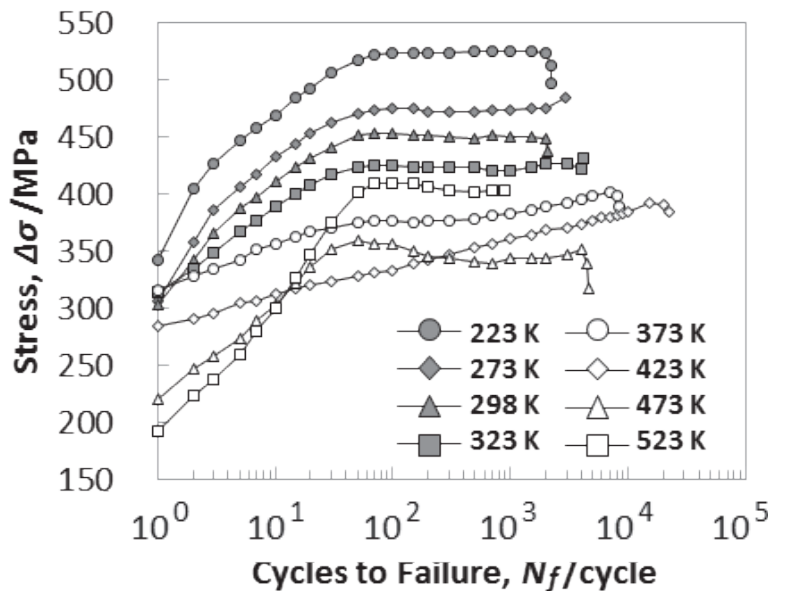

Fig. 5 (a) Temperature dependence of number of cycles to failure. (b) Changes in stress amplitudes with number of cycles at different temperatures.

decreases with increase in the temperature from $223 \mathrm{~K}$ to $473 \mathrm{~K}$, and totally disappears at $523 \mathrm{~K}$. Thus, the upper temperature limit for the strain-induced martensitic transformation, $M_{\mathrm{d}}$, is considered to be close to $473 \mathrm{~K}$.

Figure 5(a) shows the temperature dependence of the number of cycles to failure $\left(N_{\mathrm{f}}\right)$. The constituent phases determined by XRD analysis are also shown on Fig. 5(a). High $N_{\mathrm{f}}$ values are obtained in the temperature range between $373 \mathrm{~K}$ and $473 \mathrm{~K}$, and, in particular, the highest $N_{\mathrm{f}}$ of 22401 cycles was reached at $423 \mathrm{~K}$ that is placed between $M_{\mathrm{s}}{ }^{\sigma}$ and $M_{\mathrm{d}}$. At temperatures below $423 \mathrm{~K}, N_{\mathrm{f}}$ decreases with decreasing testing temperature, while at temperatures above $423 \mathrm{~K}, N_{\mathrm{f}}$ decreases rapidly with increasing testing temperature.

The stress amplitude versus the number of cycles of the specimens deformed at each deformation temperature between $223 \mathrm{~K}$ and $523 \mathrm{~K}$ are indicated in Fig. 5(b). Three types of cyclic hardening/softening characteristics are clearly correlated to the three temperature ranges divided by $M_{\mathrm{S}}{ }^{\sigma}$ $(373 \mathrm{~K})$ and $M_{\mathrm{d}}(473 \mathrm{~K})$, which are shown in Fig. 3: (i) Significant initial hardening followed by a plateau in temperature range below $M_{\mathrm{s}}{ }^{\sigma}$ (range I), (ii) moderate monotonic hardening in range between $M_{\mathrm{s}}{ }^{\sigma}$ and $M_{\mathrm{d}}$ (range II), and (iii) initial hardening, subsequent softening, with or without the secondary hardening in range above $M_{\mathrm{d}}$ (range III). The deformation at $373 \mathrm{~K}$ shows an intermediate character between the ranges I and II.

In the temperature range $\mathrm{I}\left(T<M_{\mathrm{S}}{ }^{\sigma}\right)$, the stress-induced $\varepsilon$-martensitic transformation is reported to be dominant plasticity mechanism ${ }^{7,8)}$. The lower the deformation temperature is, the more the cyclic deformation behavior can be affected by deformation-induced $\varepsilon$-martensitic transformation. The initial cyclic strain hardening occurs, and the stress amplitude saturates above 100 cycles. The stress level increases with a decrease in the deformation temperature.

On the other hand, in the temperature range III, where the $\gamma$-austenite is strongly stabilized against $\varepsilon$-martensite, a rapid increase in the dislocation density may account for the high initial hardening rate. The hardening / softening behavior in this temperature range resembles that observed in a 316-type austenitic steel ${ }^{9)}$, in which the initial hardening and subsequent softening stages are ascribed to an increase in dislocation density and rearrangement of dislocations, respectively. Furthermore, at $473 \mathrm{~K}$, the secondary hardening stage also appeared from 500 cycles leading to the final failure stage starting at approximately 4000 cycles. The specimen deformed at $523 \mathrm{~K}$ was failed without showing the secondary hardening stage at obviously lower $N_{\mathrm{f}}$ than that of the specimen deformed at $473 \mathrm{~K}$.

A distinct cyclic deformation behavior was observed at the intermediate temperatures $373<T<473 \mathrm{~K}$ (range II), where superior $N_{\mathrm{f}}$ values are obtained. The cyclic softening was suppressed and the increase in the stress was rather slow. In particular, the specimen deformed at $423 \mathrm{~K}$ that shows the highest $N_{\mathrm{f}}$ exhibited a continuous and moderate hardening behavior. Because of the deformation temperature below $M_{\mathrm{d}}$, the cyclic deformation-induced $\varepsilon$-martensite is still detected in the fatigue fractured specimen, but the Gibbs free energy difference between the $\gamma$ and $\varepsilon$ phases are considered to be small. This thermodynamic condition may affect the distinct mild hardening behavior in this range, which will be discussed in detail later. The specimen deformed at $373 \mathrm{~K}$ showed an intermediate deformation behavior between range I and II, where gradual primary hardening occurred until 80 cycles, and secondary hardening started after 500 cycles. This indicates that the change from range II to I is depending on the continuous change in the thermodynamic stability of the $\gamma$ and $\varepsilon$ phases.

Hence, we found that the observed cyclic hardening / softening behavior can be classified into three temperature ranges defined by martensitic transformation temperatures, $M_{\mathrm{s}}{ }^{\sigma}$ and $M_{\mathrm{d}}$. The temperature range which gives improved $N_{\mathrm{f}}$ is associated with the particular cyclic deformation behavior characterized by the continuous mild hardening.

\subsection{Fatigue microstructure}

Figure 6 shows phase maps ((a), (b), (c)), inverse pole figures (IPF) maps for the $\varepsilon$-martensite with respect to Loading direction (LD) $((\mathrm{d}),(\mathrm{e}))$, and the corresponding inverse pole figures ((f), (g)) after fatigue failure tested at $298 \mathrm{~K}$ ((a), (d), (f)), $423 \mathrm{~K}((\mathrm{~b}),(\mathrm{e}),(\mathrm{g}))$ and $523 \mathrm{~K}(\mathrm{c})$, respectively. In the phase maps, $\gamma$-austenite and $\varepsilon$-martensite are indicated in white and gray, respectively. Black and blue lines indicate high-angle grain boundaries $\left(15^{\circ}<\theta\right)$ and low-angle grain boundaries $\left(2^{\circ}<\theta<15^{\circ}\right)$, respectively. The deformation tem- 

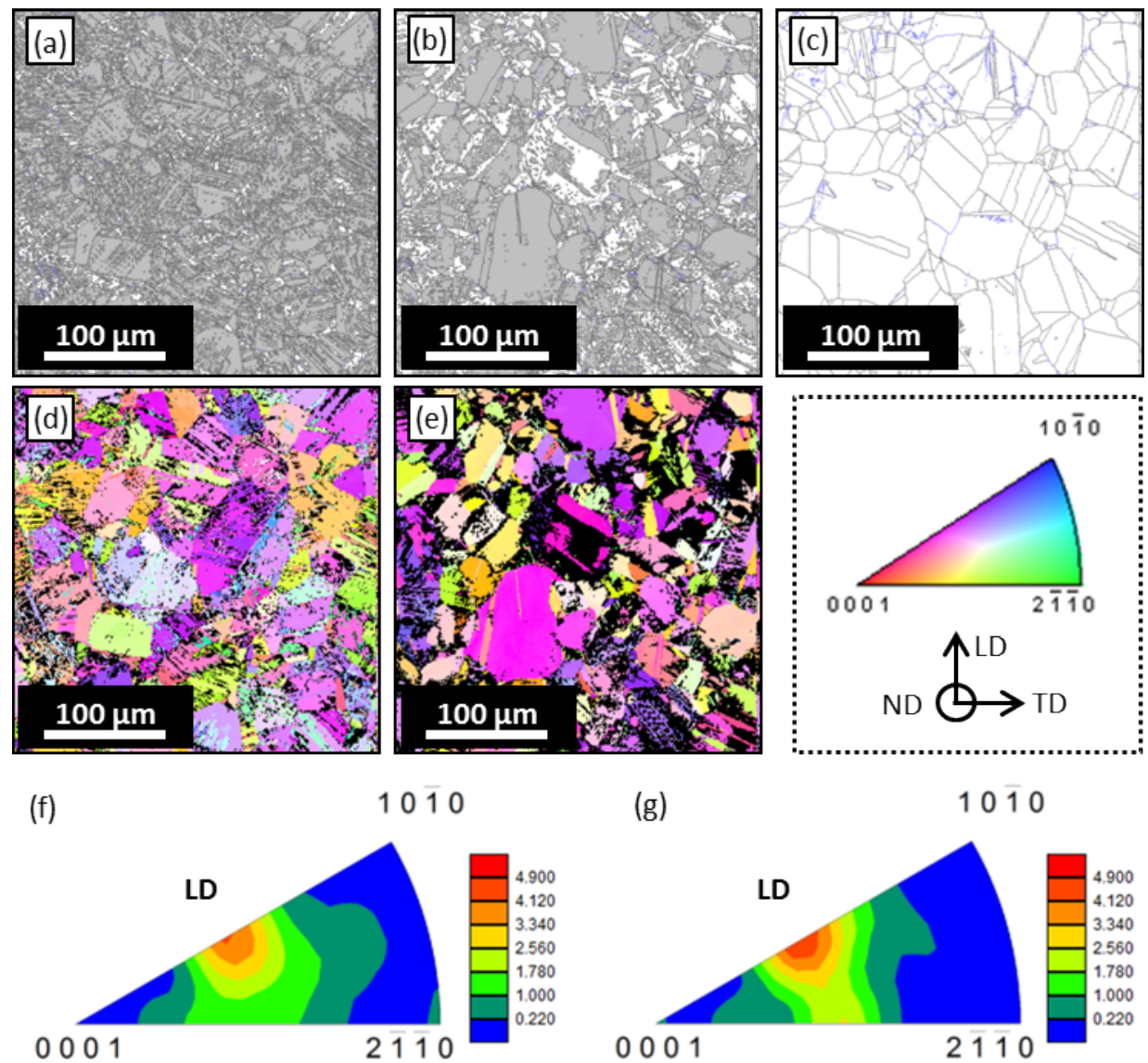

Fig. 6 Microstructures after fatigue failure tested at different temperatures. (a,b,c) Phase maps obtained at $298 \mathrm{~K}$ (a), $423 \mathrm{~K}$ (b) and $523 \mathrm{~K}$ (c). (d,e) inverse pole figure (IPF) maps for $\varepsilon$-martensite and corresponding pole figures for LD direction at $298 \mathrm{~K}$ (d,f) and at $423 \mathrm{~K}$ (e,g).

peratures 298, 423 and $523 \mathrm{~K}$ are selected as representatives for three types of deformation behavior related to the temperature ranges characterized in Section 3.1; namely, $298 \mathrm{~K}$ as a representative for the temperature ranges $\mathrm{I}\left(T<M_{\mathrm{S}}{ }^{\sigma}\right)$, $423 \mathrm{~K}$ for II $\left(M_{\mathrm{s}}^{\sigma}<T<M_{\mathrm{d}}\right)$, and $523 \mathrm{~K}$ for III $\left(M_{\mathrm{d}}<T\right)$.

Phase maps (Figs. 6(a), (b) and (c)) show that the microstructure after fatigue failure in the temperature ranges I, II, and III are characterized by the ratio of area fractions of $\varepsilon$-phase and $\gamma$-phase. In the temperature range $\mathrm{I}\left(T<M_{\mathrm{s}}{ }^{\sigma}\right)$ where the deformation-induced martensitic transformation is reported to dominate the plastic deformation ${ }^{7,8)}$, very large amount of $\varepsilon$-martensite is observed (Fig. 6(a)). The deformation-induced martensitic transformation is still active in the temperature range II, as shown in Fig. 6(b); however, its contribution to plastic deformation is considered to be smaller than that in the temperature range I. The martensitic transformation no longer contributes to plastic deformation when deformation temperature is elevated to the range III, that is above $M_{\mathrm{d}}$.

IPF maps of the $\varepsilon$-phase and the corresponding inverse pole figures with respect to the deformation axis (LD) are represented in Fig. 6(d) and (f), and Fig. 6(e) and (g), respectively. A fiber texture nearly oriented to [10-12]//LD is developed both in temperature ranges I and II. Because the uniaxial tensile deformation induces the $\varepsilon$-martensite variant with the highest Schimd factor and the defined crystallographic orientation relationship between the $\gamma$ - and $\varepsilon$-phases, which is known as Shoji-Nishiyama orientation relationship, the basal plane of the deformation-induced $\varepsilon$-martensite is inclined from the deformation axis. The angle between the basal plane of $\varepsilon$-martensite and deformation axis giving the highest Schmid's factor is $45^{\circ}$. As a consequence, both basal and prism planes of the $\varepsilon$-crystal are rarely parallel to the observed plane that is parallel to the deformation axis. Instead, the planes close to the (10-12), approximately $43.21^{\circ}$ apart from the basal plane, appear on the observed plane.

\subsection{Characteristics in fracture surface}

Figure 7 shows low magnification SEM images of fracture surfaces for the specimens deformed to fatigue failure at $298 \mathrm{~K}$ (range I), $423 \mathrm{~K}$ (range II), $523 \mathrm{~K}$ (range III). Typical brittle and ductile characteristics of fracture surface were observed at lower (range I) and higher (range III) temperatures, respectively. The fracture surface for the intermediate temperature (range II) exhibits the mixture of them.

Figures 8(a) and (b) show enlarged images of typical brittle fracture surfaces taken at $298 \mathrm{~K}$ (range I). Figure 8(a) shows flat surface with shallow dimples, which is reported to be a quasi-cleavage fracture at the $\gamma / \varepsilon$ boundary in tensile deformation $^{10)}$, and cyclic deformation ${ }^{11)}$. The dimples are in arrays along $\{111\}$ traces, reflecting the collision of the different $\varepsilon$-variants on the rapturing $\gamma / \varepsilon$ interface. Figure $8(b)$ shows step-like surface pattern that resembles to a typical fracture surface on [10-10] prism planes called as 'fluting' in HCP metals such as $\alpha$-Titanium alloys ${ }^{12)}$. Figures 9 (a) and (b) show enlarged images of typical ductile fracture surfaces for 

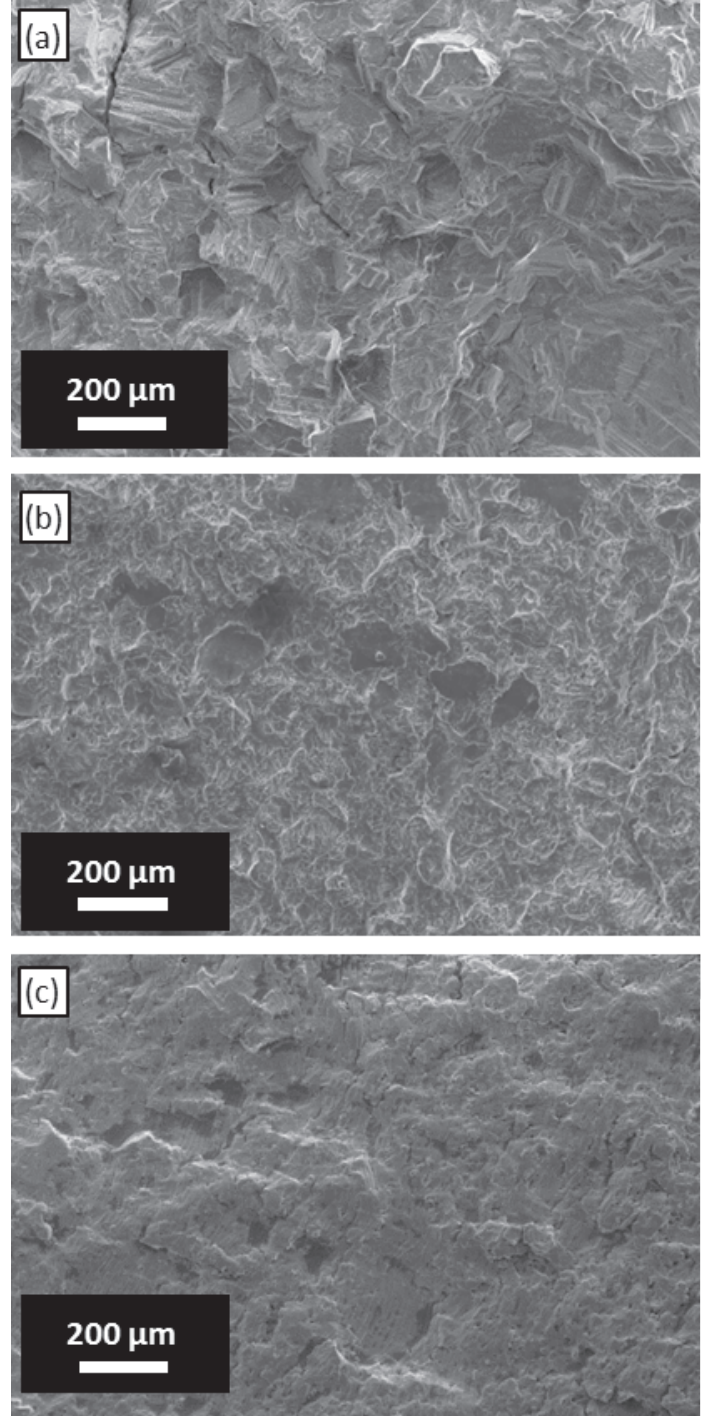

Fig. 7 Low magnification SEM images for fatigue fracture surfaces in the specimens tested at (a) $298 \mathrm{~K}$ (b) $423 \mathrm{~K}$ and (c) $523 \mathrm{~K}$
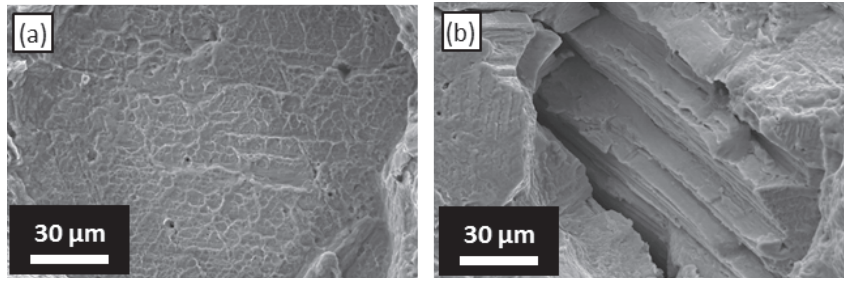

Fig. 8 Enlarged SEM images of typical brittle fracture surfaces in the specimen tested at $298 \mathrm{~K}$, showing (a) quasi-cleavage fracture and (b) fluting.
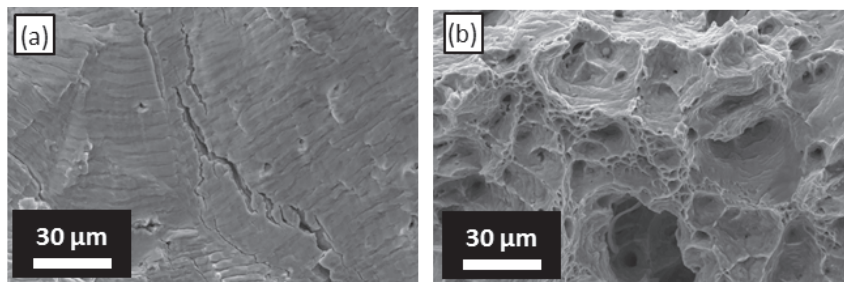

Fig. 9 Enlarged SEM images of typical ductile fracture surfaces after fatigue at $523 \mathrm{~K}$, showing (a) striations and (b) dimples.
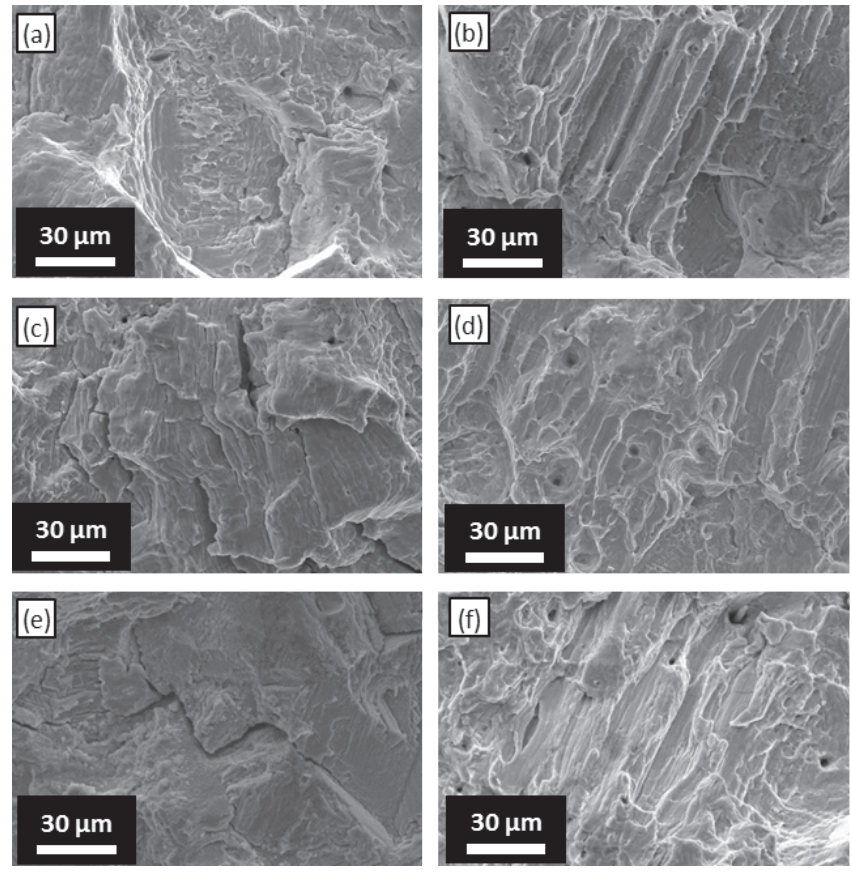

Fig. 10 Enlarged SEM images of typical brittle fracture surfaces after fatigue at $523 \mathrm{~K}$ showing (a) quasi-cleavage fracture, (b) fluting, (c) striations, (d) dimples, (e) river pattern and (f) ridge-like pattern.

high temperature range III. Figure 9(a) shows striations, which are known as a typical fracture surface pattern appearing in an early stage of ductile fatigue crack propagation under cyclic deformation ${ }^{13)}$. Figure 9(b) shows deep and large dimples, which characterize that here is the final rupture place.

Figures 10(a-f) show enlarged images of four typical brittle/ductile fracture surfaces observed for intermediate temperature range II. Figures 10(a) and (b) exhibit quasi-cleavage fracture and fluting, respectively. They are similar to those observed in the low temperature range I. Figures 10(c) and (d) show striations and dimples, respectively. They are similar to those observed in the high temperature range III. Figures 10(e) and (f) show examples of various irregular surface patterns, which cannot be classified to either of the above typical brittle or ductile fracture surface patterns. Figure 10(e) shows river patterns of cleavage plane and steps. Figure 10(f) shows ridge-like patterns with ductile nature. It should be noted that the majority of the surface patterns in the temperature range II are the irregular types rather than the typical brittle patterns (quasi-cleavage and flutings) and typical ductile patterns (dimples and striations).

\section{Discussion}

\subsection{Transition of deformation modes under cyclic load- ing}

In this research, effect of deformation temperature on cyclic deformation behavior of the $\mathrm{Fe}-28 \mathrm{Mn}-6 \mathrm{Si}-5 \mathrm{Cr}$ shape memory alloy was investigated systematically. It was revealed that the fatigue deformation microstructures and fatigue fracture surfaces can be classified into the following three groups with respect to the martensitic transformation temperatures, $M_{s}{ }^{\sigma}$ and $M_{\mathrm{d}}$ : range I (below $M_{\mathrm{s}}{ }^{\sigma}$ ), range II (between $M_{\mathrm{s}}{ }^{\sigma}$ and 
$M_{\mathrm{d}}$ ), and range III (above $M_{\mathrm{d}}$ ). The plastic deformation modes accounting for the deformation characteristics in each temperature ranges can be interpreted as shown below.

\subsubsection{Cyclic deformation associated with the $\gamma \rightarrow \varepsilon$ transformation and the plastic deformation of the $\varepsilon$-martensite}

Below $M_{\mathrm{s}}^{\sigma}$ (range I), the stress-assisted $\gamma \rightarrow \varepsilon$ martensitic transformation is reported to occur under tensile loading ${ }^{7)}$, which may also occur throughout cyclic loading. Our previous LCF tests on various $\mathrm{Fe}-\mathrm{Mn}-\mathrm{Si}$-based alloys at room temperature suggested that the $\varepsilon$-martensite should gradually increase under cyclic deformation, probably accompanying reversible forward/reverse transformation (reversible twoway transformation) of the tension- and compression-induced $\varepsilon$-marntesite ${ }^{10,14,15)}$.

Below $M_{\mathrm{s}}$, the $\varepsilon$-martensite is much more stable than above $M_{\mathrm{s}}$, and the some amount of $\varepsilon$-phase already exists in the initial microstructure. This difference does not change the cyclic deformation behavior, namely, initial hardening followed by a plateau. However, the stress level of the plateau continuously increases, when deformation temperature is decreased across $M_{\mathrm{s}}$.

The most plausible mechanism responsible for the initial hardening is the cyclic-deformation-induced martensitic transformation. Irrespective of the deformation temperature, the cyclic stress is saturated above 100 cycles, where the $\varepsilon$-martensite becomes dominant, and further cyclic deformation may be implemented by plastic deformation of the $\varepsilon$-martensite. The higher stress level inherent to the lower temperatures is a normal temperature response of the stresses required for the plastic deformation of the $\varepsilon$-phase either by slip or twinning.

The features of fracture surface in this temperature range represent brittle characteristic as the crack propagations on prism planes (fluting) and on the $\gamma / \varepsilon$ interfaces (quasi-cleavage). In spite of the brittle characteristics, the $N_{\mathrm{f}}$ increases with increasing deformation temperature. The reversible martensitic transformation between the $\gamma$ - and $\varepsilon$-phases is a possible reason for the improved $N_{\mathrm{f}}$ values. The reverse martensitic transformation of the tension- or compression-induced $\varepsilon$-martensite is reported to occur when the deformation direction when the deformation direction is inversed, from tension to compression, or compression to tension. Such reversible microstructural changes accompanying the back-and-forth movement of partial dislocations may suppress the local accumulation of dislocations and delay the progress of the fatigue.

\subsubsection{Cyclic deformation of the $\gamma$-phase with low stack- ing fault energy}

Above $M_{\mathrm{d}}$ (range III), the $\gamma \rightarrow \varepsilon$ martensitic transformation does not occur, and the cyclic deformation is governed by plastic deformation of the $\gamma$-austenite. It should be noted that the $N_{\mathrm{f}}$ value is still large at $473 \mathrm{~K}$ that is about $M_{\mathrm{d}}$ where the $\varepsilon$-martensite fraction in the fatigue fractured specimen is negligibly small. This suggests that the extended dislocations alone can improve the $N_{\mathrm{f}}$ even without forming the $\varepsilon$-martensite, as long as the dissociation width of the moving partial dislocations is sufficiently wide.

The significant initial hardening shown in this temperature range III is ascribed to increase in dislocation densities. The following softening stage implies the existence of some relaxation mechanism associated with rearrangement of dislocation structures ${ }^{9}$. The specimen deformed at $473 \mathrm{~K}$ exhibits the secondary hardening stage and longer $N_{\mathrm{f}}$ than the specimen deformed at $523 \mathrm{~K}$ that failed without secondary hardening stage. Note that the former shows much lower cyclic stresses than the latter in spite of lower deformation temperature. This is attributable to the extension of dislocations that is likely to make the back-and-forth movement of dislocation under cyclic loading reversible and confined on an identical $\{111\}$ planes without cross slips.

\subsubsection{Cyclic deformation at between $M_{\mathrm{s}}{ }^{\sigma}$ and $M_{\mathrm{d}}$}

In the temperature range II $\left(M_{\mathrm{s}}^{\sigma}<T<M_{\mathrm{d}}\right)$, the $\varepsilon$-martensite still forms during cyclic deformation, but the contribution of the $\gamma$ dislocation glide increases than in the lower temperature range I. The growth of the $\varepsilon$-martensite is significantly suppressed compared with the lower temperatures. There are two possible reasons realizing the superior $N_{\mathrm{f}}$ values in this temperature range. Firstly, the $\gamma$ - and $\varepsilon$-phase stabilities are close to each other in this temperature range, and it is considered that reversible two-way martensitic transformations between the $\gamma$ - and $\varepsilon$-phases can easily occur. Secondly, the SFE of the remaining $\gamma$-phase is also lower than that in the higher temperature range III, and thus the back-and-forth movement of the extended dislocations is more strongly confined on an identical slip plane. In both cases, partial dislocations move in the most reversible manner among all the testing temperatures. The moderate cyclic hardening is observed and no significant softening stage appears in this temperature range. It implies a slow change in the microstructure, namely, a slow increase in the volume fraction of the $\varepsilon$-martensite, and insignificant development of the rearranged dislocation structures $^{9)}$.

Both ductile and brittle features are observed in fracture surface patterns, which are different from either of higher or lower temperature ranges. The quasi-cleavage surface and flutings characterizing the brittle crack propagation along the $\gamma / \varepsilon$ interfaces and through the $\varepsilon$-phase are also observed, but their area fractions are significantly reduced. The dimples and striations indicating ductile fracture in the remaining $\gamma$-phase also appear, occasionally. These microstructural and fractographic characteristics suggest that the coexistence of the reversible two-way martensitic transformation that was discussed in Subsection 4.1.1 and the extended dislocation glide that was discussed in Subsection 4.1.2 should cause the highest $N_{\mathrm{f}}$ values in this temperature ranges.

We can thus point out two possible causes for the improved $N_{\mathrm{f}}$ : the thermodynamic balance between the two phases and wide extension of the dislocations. A question arises from this discussion; whether the two-way transformation has any positive effect on $N_{\mathrm{f}}$ or merely occur as a result of wide extension of dislocations. Recently, Li et al. ${ }^{16)}$ reported that the $\varepsilon$-martensite is formed at around propagating fatigue cracks and discussed its possible effects on the crack growth suppression. Further investigation in this aspect is crucially important.

\subsection{Equivalence between temperature and chemical composition}

The thermodynamic phase stability and the extension 
width of dislocations are not only dependent on temperature but also on chemical composition. In the previous studies ${ }^{3,11}$ LCF properties of Fe-Mn, Fe-Mn-Si, Fe-Mn-Si-Al, and Fe$\mathrm{Mn}-\mathrm{Cr}-\mathrm{Ni}-\mathrm{Si}$ alloys have been reported. Nikulin et al. investigated LCF properties of Fe-30Mn-(1- $x) \mathrm{Si}-x \mathrm{Al}(x=0,1,2,3$, 4, 5, 6 mass\%) alloys. The Fe-30Mn-6Si alloy is a typical Fe-Mn-Si-based shape memory alloy that undergoes the deformation-induced $\varepsilon$-martensitic transformation as a dominant plastic deformation mechanism. The Fe-30Mn-4Si-2Al $(x=2)$ and $\mathrm{Fe}-30 \mathrm{Mn}-3 \mathrm{Si}-3 \mathrm{Al}(x=3)$ are transformation-/ twinning-induced plasticity (TRIP/TWIP) steels, which exhibit the martensitic transformation and mechanical $\gamma$-twinning as the secondary deformation mechanisms following the preceding dislocations glide. With increasing $\mathrm{Al}$ content, the $\gamma$-austenite is more stabilized with respect to the $\varepsilon$-martensite and the SFE of the austenite increases. The highest $N_{\mathrm{f}}$ of approximately 8000 cycles was obtained at room temperature in the Fe-30Mn-4Si-2Al alloy subjected to LCF at the total strain range of $0.02^{10)}$ that is identical to the present strain range. The Fe-30Mn-4Si-2Al alloy exhibited the cyclic deformation-induced $\varepsilon$-martensite and glide of extended dislocations, similar to the present alloy deformed at $423 \mathrm{~K}$. The alloys with lower Al concentrations $(x<2)$ showed more pronounced cyclic-deformation-induced martensitic transformation, and $N_{\mathrm{f}}$ decreased, similar to the present alloy deformed at lower temperature range I. The alloys with higher Al concentrations $(x>2)$ showed no $\varepsilon$-martensite, and $N_{\mathrm{f}}$ decreased with increasing $\mathrm{Al}$ concentration, as in the present alloy deformed in higher temperature range III.

For both of $\varepsilon$-martensitic transformation and the dislocation extension, the SFE is the critical parameter to predict the deformation characters. In low-SFE FCC metals, dislocations are easily extended into a couple of partial dislocations and stacking fault forms in between them, and the width of the extension increases with decreasing SFE. Recently, the value of SFE is also used as a measure for predicting the deformation mode operated under tensile load among $\gamma \rightarrow \varepsilon$ martensitic transformation, mechanical $\gamma$-twinning, and extended dislocation glide, all of which involve regularly or irregularly integrated motion of the units of partial dislocations-stacking fault as an elementary process. Allain et al. ${ }^{17)}$ reported SFE dependence of deformation modes in Fe-22Mn-0.6C alloy. $\varepsilon$-martensitic transformation only occurs for SFE of $\Gamma<$ $18 \mathrm{mJm}^{-2}$, while mechanical twinning takes place for $12 \mathrm{mJm}^{-2}<\Gamma<35 \mathrm{mJm}^{-2}$. Because the stacking fault is regarded as the thin $\varepsilon$-phase with two $\{111\}$ atomic layers, SFE is obtained by calculating the Gibbs's free energy difference between the $\gamma$ - and $\varepsilon$ - phases and the interfacial energy as follows.

$$
\Gamma=2 \rho \cdot \Delta G^{\gamma \rightarrow \varepsilon}+2 \sigma^{18)}
$$

Where $\rho$ is the molar curface density along $\left\{\begin{array}{lll}1 & 1 & 1\end{array}\right\}$ planes, $\Delta G^{\gamma \rightarrow \varepsilon}$ is the difference in molar Gibbs's energy between the $\gamma$-austenite to $\varepsilon$-martensite phase, and $\sigma$ is the interfacial energy per unit area of the phase boundary. The SFE is commonly used as a scale for predicting both the deformation mode selection and the extension width of dislocations in the $\gamma$-austenite.

In this section, the SFE is calculated for the Fe-28Mn-6Si$5 \mathrm{Cr}$ alloy at various temperatures and $\mathrm{Fe}-30 \mathrm{Mn}-(6-x) \mathrm{Si}-x \mathrm{Al}$
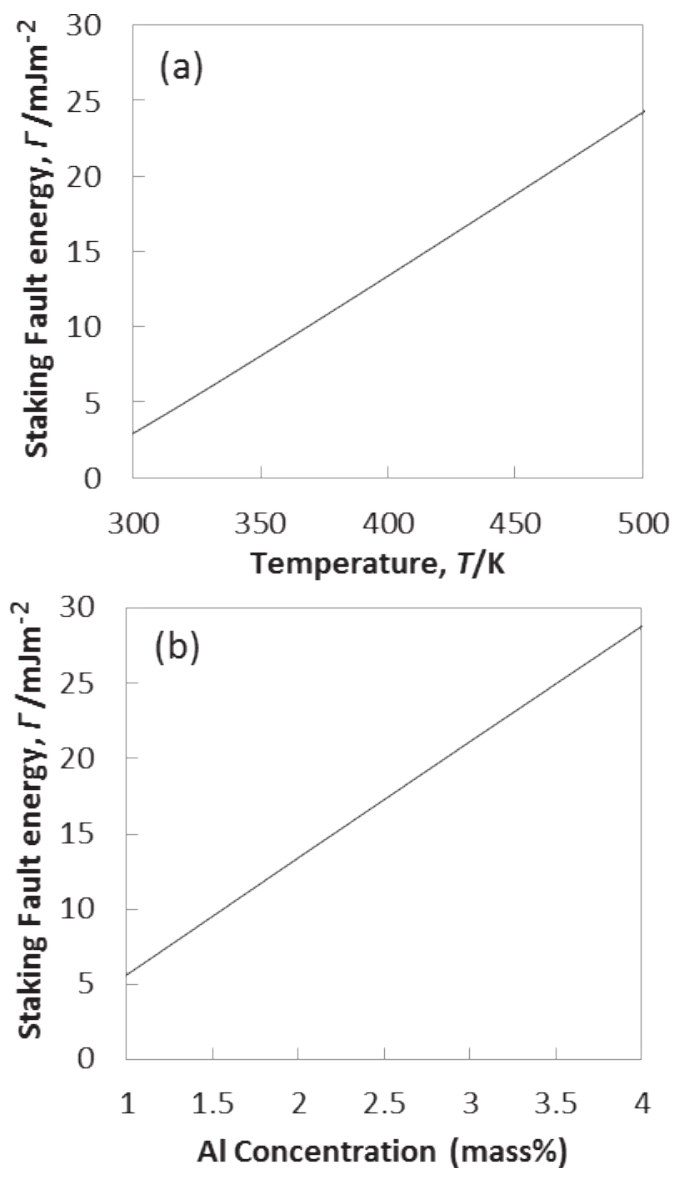

Fig. 11 (a) Calculated SFE as a function of temperature in Fe-28Mn-6Si$5 \mathrm{Cr}(223 \leq T(\mathrm{~K}) \leq 523)$. (b) Calculated SFE as a function of Al concentration in Fe-30Mn- $(6-x) \mathrm{Si}-x \mathrm{Al}(0 \leq x(\operatorname{mass} \%) \leq 4)$.

alloys with various compositions, and the equivalence between the temperature and the composition, and the SFE dependence of the deformation mode selection rule are verified in a quantitative manner.

Various parameters for the Gibbs free energy difference between the $\gamma$-and $\varepsilon$-phases and the SFE are proposed for various alloy systems ${ }^{17-20)}$. In the present research, SFE calculation method in high-Mn steels including $\mathrm{Cr}$ developed by Curtze et al. ${ }^{21)}$ is applied to both of the $\mathrm{Fe}-28 \mathrm{Mn}-6 \mathrm{Si}-5 \mathrm{Cr}$ alloy at various temperatures and the Fe-Mn-Si-Al alloys with different compositions at room temperature.

Figure 11(a) indicates the values of SFE as a function of temperature calculated for the Fe-28Mn-6Si-5Cr alloy (223 $\leq$ $T(\mathrm{~K}) \leq 523$ ). Figure 11(b) indicates the values of SFE as a function of $\mathrm{Al}$ concentration calculated for Fe-30Mn-(6- $x$ )Si$x \mathrm{Al}$ alloy $(0 \leq x(\operatorname{mass} \%) \leq 4)$. The SFE of Fe-28Mn-6Si-5Cr alloy increases with temperature, from $\Gamma=2.7 \mathrm{mJm}^{-2}$ at $298 \mathrm{~K}$ to $\Gamma=26.4 \mathrm{mJm}^{-2}$ at $523 \mathrm{~K}$. SFE of Fe-30Mn-(6- $\left.x\right)$ $\mathrm{Si}-x \mathrm{Al}$ alloys increases with $\mathrm{Al}$ content, from $\Gamma=5.6 \mathrm{mJm}^{-2}$ at 1 mass $\%$ to $\Gamma=28.8 \mathrm{mJm}^{-2}$ at 4 mass $\%$. These results indicate an equivalency of SFE dependence temperature and chemical composition. This fact permits to discuss the variation of fatigue life with temperature and with chemical composition using the value of SFE as a common scale.

Figure 12 shows the relationship between fatigue life and the SFE of the Fe-28Mn-6Si-5Cr alloy with different deformation temperatures and the $\mathrm{Fe}-30 \mathrm{Mn}-(6-x) \mathrm{Si}-x \mathrm{Al}$ alloys 


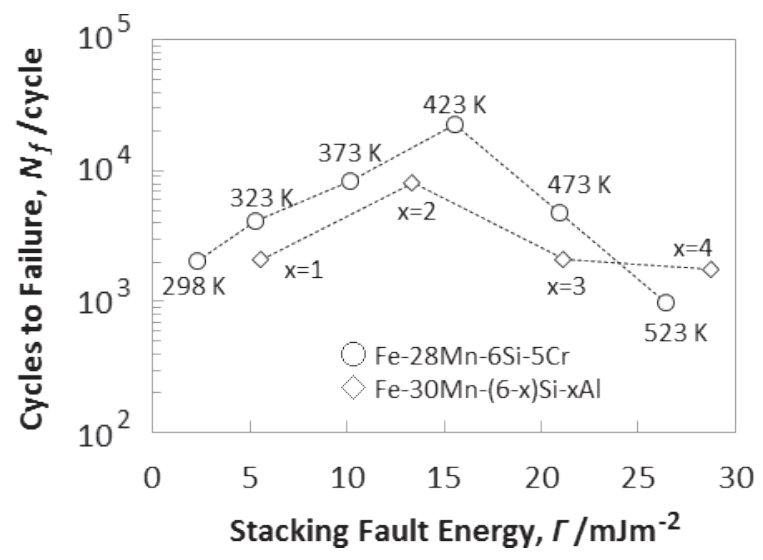

Fig. 12 Relationship between fatigue life and SFE in $\mathrm{Fe}-28 \mathrm{Mn}-6 \mathrm{Si}-5 \mathrm{Cr}$ with different deformation temperatures and in Fe-30Mn-(6- $x) \mathrm{Si}-x \mathrm{Al}$ alloys with different compositions.

with different compositions, respectively. Maximum fatigue life of the $\mathrm{Fe}-28 \mathrm{Mn}-6 \mathrm{Si}-5 \mathrm{Cr}$ alloy is obtained at $15.5 \mathrm{mJm}^{-2}$. On the other hand, the maximum $N_{\mathrm{f}}$ of Fe-30Mn- $(6-x) \mathrm{Si}-x \mathrm{Al}$ alloys are obtained at $13.4 \mathrm{mJm}^{-2}$. Accordingly, the equivalency between temperature and composition in terms of the optimum condition to improve the $N_{\mathrm{f}}$ is verified in a quantitative manner through calculating the SFE as the common scale. It should be noted that the best SFE values for improving $N_{\mathrm{f}}$ obtained in this study calculation is $\Gamma \approx 15 \mathrm{mJm}^{-2}$ that close to that proposed in the literature ${ }^{3)}$, i.e., $\Gamma \approx 20 \mathrm{mJm}^{-2}$.

\section{Conclusions}

(1) The temperature dependence of low-cycle fatigue life and the corresponding cyclic hardening/softening behavior can be classified into three temperature ranges with respect to the martensitic transformation temperatures.

(2) Below $M_{\mathrm{s}}{ }^{\sigma}$, cyclic deformation-induced martensitic transformation and the plastic deformation of the $\varepsilon$-martensite cause the initial hardening followed by a plateau. In spite of the brittle crack propagation along the $\gamma / \varepsilon$ interfaces and inside the $\varepsilon$-martensite, the alloy is resistant against the low-cycle fatigue due to the reversible twoway martensitic transformation, which improves $N_{\mathrm{f}}$ as the deformation temperature increase.

(3) Above $M_{\mathrm{d}}$, no $\varepsilon$-martensite is formed and the plastic deformation of the $\gamma$-phase dominates the cyclic deformation. With decrease in deformation temperature $N_{\mathrm{f}}$ increases owing to the wider dissociation width of dislocations that promote the reversible back-and-forth movement of dislocations.

(4) In the medium temperature range between $M_{\mathrm{s}}{ }^{\sigma}$ and $M_{\mathrm{d}}$, the highest fatigue life of approximately 22,400 cycles was obtained in the alloy deformed at $423 \mathrm{~K}$ at the total strain range of 0.02 . The back-and-forth movement of partial dislocations associated both with the reversible martensitic transformation and the glide of extended dislocation is responsible for the superior $N_{\mathrm{f}}$. The cyclic hardening is gradual and monotonic due to delayed growth of the cyclic-deformation-induced $\varepsilon$-martensite.

(5) The stacking fault energy of the Fe-28Mn-6Si-5Cr calcu- lated by thermodynamic parameters proposed by Curtze et al. is $15.5 \mathrm{mJm}^{-2}$ at $423 \mathrm{~K}$ where the highest $N_{\mathrm{f}}$ is obtained. The temperature dependence of the $N_{\mathrm{f}}$ and the corresponding LCF characteristics of the present alloy agree well with the composition dependence of those in the Fe-Mn-Si-Al alloys.

(6) The best condition for improving the $N_{\mathrm{f}}$ can be expressed as the deformation between $M_{\mathrm{s}}{ }^{\sigma}$ and $M_{\mathrm{d}}$. Possible reasons for this are thermodynamic balance between the $\gamma$ - and $\varepsilon$-phases that promotes the cyclic two-way transformation and/or the wider extension of dislocations that enhances the reversibility of the back-and-forth movement of partial dislocations.

\section{Acknowledgments}

A Part of this work was supported by Grant-in-Aid for Scientific Research Fund (A) (No. 25249099) from the Japan Society for the Promotion of Science (JSPS). We would like to acknowledge the Materials Manufacturing and Engineering Station, NIMS, for the materials processing. We also would like to express our sincere gratitude to Prof. Kaneaki Tsuzaki, Kyushu University, for his continuous encouragement as well as the valuable comments on the manuscript.

\section{REFERENCES}

1) A. Sato, E. Chishima, K. Soma and T. Mori: Acta Metall. 30 (1982) 1177-1183.

2) T. Maruyama, T. Kurita, S. Kozaki, K. Andou, S. Farjami and H. Kubo: Mater. Sci. Technol. 24 (2008) 908-912.

3) T. Sawaguchi, I. Nikulin, K. Ogawa, K. Sekido, S. Takamori, T. Maruyama, Y. Shiba, A. Kushibe, Y. Inoue and K. Tsuzaki: Scr. Mater. 99 (2015) 49-52.

4) T. Sawaguchi: Ferrum 20 (2015) 96-102 (In Japanese).

5) L. Remy and A. Pineau: Mater. Sci. Eng. 28 (1977) 99-107.

6) O. Bouaziz, S. Allain, C.P. Scott, P. Cugy and D. Barbier: Curr. Opin. Solid State Mater. Sci. 15 (2011) 141-168.

7) M. Andersson, R. Stalmans and J. Agren: Acta Mater. 46 (1998) 3883 3891.

8) G.B. Olson and M. Cohen: J. Less-Com Met. 28 (1972) 107-118.

9) M.S. Pham, C. Solenthaler, K.G.F. Janssens and S.R. Holdsworth: Mater. Sci. Eng. A 528 (2011) 3261-3269.

10) S. Takaki, T. Furuya and Y. Tokunaga: ISIJ Int. 30 (1990) 632-638.

11) I. Nikulin, T. Sawaguchi and K. Tsuzaki: Mater. Sci. Eng. A 587 (2013) 192-200.

12) A.L. Pilchak and J.C. Williams: Metall. Mater. Trans., A Phys. Metall. Mater. Sci. 41 (2010) 22-25.

13) Mirko Klesnil and Petr Lukas: Fatigue of Metallic Materials (Institute of Physical Metallurgy of the Czechoslovak Academy of Sciences, Brno, Czechoslovakia, 1992) pp. 92-97.

14) T. Sawaguchi, P. Sahu, T. Kikuchi, K. Ogawa, S. Kajiwara, A. Kushibe, M. Higashino and T. Ogawa: Scr. Mater. 54 (2006) 1885-1890.

15) T. Sawaguchi, L.-G. Bujoreanu, T. Kikuchi, K. Ogawa, M. Koyama and M. Murakami: Scr. Mater. 59 (2008) 826-829.

16) H. Li, M. Koyama, T. Sawaguchi, K. Tsuzaki and H. Noguchi: Philos. Mag. Lett. 95 (2015) 303-311.

17) S. Allain, J.-P. Chateau, O. Bouaziz, S. Migot and N. Guelton: Mater. Sci. Eng. A 387-389 (2004) 158-162.

18) G.B. Olson and M. Cohen: Metall. Trans. A. 7 (1976) 1915-1923.

19) L. Rémy and A. Pineau: Mater. Sci. Eng. 36 (1978) 47-63.

20) O. Grassel, G. Frommeyer, C. Derder and H. Hofmann: J. Phys. IV C5 (1997) 383-388.

21) S. Curtze, V.-T. Kuokkala, A. Oikari, J. Talonen and H. Hanninen: Acta Mater. 59 (2011) 1068-1076. 